УДК 577.2

DOI: $10.33184 /$ spbgb-2021-09-21.24

\title{
Полиморфные варианты гена NOX1 и риск развития сахарного диабета второго типа
}

\author{
() Е. Ю. Клёсова*, Ю. Э. Азарова, А. В. Полоников
}

Курский государственный медицинский университет

Россия, 305041 г. Курск, улица Карла Маркса, 3.

*Email: ecless@yandex.ru

Установлена ассоциация локуса rs5921678 гена NOX1 с риском развития сахарного диабета 2 типа у женщин в русской популяции.

Ключевые слова: NOX1, однонуклеотидный полиморфизм, NADPH-оксидаза, индекс массы тела, глюкоза крови, сахарный диабет 2 типа.

NOX1 - член семейства фрерментов NADPH-оксидазы, главной функцией которых является генерация супероксид-аниона. NADPH-оксидаза 1 (рисунок 1) представляет собой пиридиннуклеотид-зависимую оксидоредуктазу, участвующую в регуляции клеточного $\mathrm{pH}[1]$.

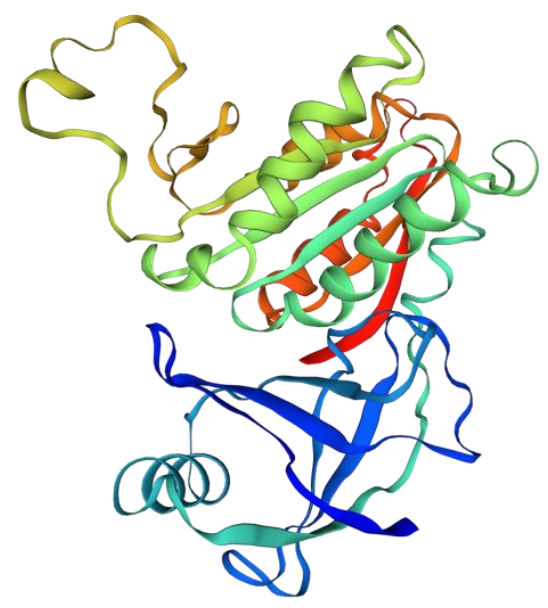

Рис. 1. Трехмерная структура фермента NADPH-оксидазы 1.

Активность NADPH-оксидазы 1 в значительной степени определяет баланс в редокссистеме. Именно нарушения в этой системе являются причиной развития окислительного стресса и составляют основу патогенеза сахарного диабета 2 типа (СД2), одного и самых распространенных метаболических заболеваний в мире [2].

Целью настоящей работы стало изучение ассоциаций полиморфных однонуклеотидных вариантов rs5921678, rs5921668, rs5921682 гена NOX1 с биохимическими показателями плазмы крови, а также с риском у больных СД2 женщин и здоровых лиц. 
В исследование принимали участие 2012 женщин, из них 988 человек (средний возраст 62,2ะ6,7 лет) составили группу больных СД2, получавших стационарное лечение на базе эндокринологического отделения Курской городской клинической больницы скорой медицинской помощи с декабря 2016 по октябрь 2019 гг, и 1024 вошли в группу контроля доноры областной станции переливания крови. У всех участников исследования проводили однократный забор 10 мл крови натощак в вакуумные пробирки с ЭДТА (для генетического тестирования) и гепарином лития (для биохимического анализа). Геномную ДНК выделяли колоночным методом с помощью набора QIAamp DNA blood kit (QIAGEN) на автоматической станции QiaCube (QIAGEN, Германия). Генотипирование полиморфизмов гена NOX1 проводили с использованием технологии IPLEX на геномном времяпролетном масс-спектрометре MassArray Analyzer 4 (Agena Bioscience, США). Концентрации перекиси водорода и глутатиона в плазме крови определяли с помощью наборов OxiSelect ROS/RNS Assay kit (Cell Biolabs), GSH/GSSG Assay kit (Abcam) фрлуориметрическим методом на микропланшетном ридере Varioscan Flash (Thermo Fisher Scientific, США). Концентрации глюкозы, гликированного гемоглобина, С-пептида, общего холестерина, липопротеинов высокой и низкой плотности (ЛВП, ЛНП) и триацилглицеролов (ТАГ) определяли на полуавтоматическом биохимическом анализаторе Clima MC-15 (RAL, Испания) стандартными наборами реагентов фирмы «Диакон-ДС» (Россия). Ассоциации генотипов с риском СД2 изучали методом логистической регрессии с поправкой на пол, возраст и ИМТ с помощью программы SNPStats [3].

C помощью онлайн-программы GTEx Portal [4], мы провели анализ тканеспецифичных эфрфектов минорных аллелей изучаемых SNPs и обнаружили, что носители генотипа T/T rs5921678, T/T rs5921668 и G/G rs5921682 имеют более низкую экспрессию NOX1 в широком спектре тканей тканей.

Генотип T/T rs5921678 ассоциировался с пониженным риском СД2 у женщин (OR 0,73, $95 \% \mathrm{Cl}$ 0.57-0.93, $\mathrm{P}=0.012$, рецессивная модель). Ассоциация осталась значимой и после введения поправок на возраст и ИМТ (OR 0,75, 95\% Cl 0.58-0.97, $\mathrm{P}_{\mathrm{adj}}=0.028$ ). Частоты аллелей и генотипов rs5921668 и rs5921682 между группами больных СД2 и контроля статистически значимо не отличались ( $>>0.05)$.

Анализ неравновесия по сцеплению показал, что rs5921678 сцеплен c rs5921668 (D`=0,9212, $P<0,0001$, Таблица 1).

Таблица 1. Неравновесие по сцеплению между полиморфными вариантами гена NOX1.

\begin{tabular}{|c|c|c|c|}
\hline \multirow{2}{*}{ SNP ID } & rs5921668 & rs5921678 & rs5921682 \\
\hline \multirow{2}{*}{ rs5921668 } & & 0.1841 & -0.0673 \\
\cline { 2 - 4 } & & 0.9212 & 0.4327 \\
\hline \multirow{2}{*}{ rs5921678 } & & -0.0856 \\
\cline { 2 - 4 } & & 0.4705 \\
\hline $\begin{array}{l}\text { Показатели неравновесия по сцеплению между SNPs: верхние } \\
\text { ячейки - D (заливка серым), нижние - D. Представлены только } \\
\text { статистически значимые показатели неравновесия по сцепле- } \\
\text { нию }\left(\mathrm{P}<1.0^{\star} 10^{-9}\right) .\end{array}$ \\
\hline
\end{tabular}

Анализ частот гаплотипов установил, что гаплотип rs5921668-A- rs5921678-T- rs5921682-A оказывает протективный эффеект на риск развития заболевания (OR 0,68, 95\% Cl 0.500.91, $\mathrm{p}_{\mathrm{adj}}=0.011$, Таблица 2). 
Таблица 2. Распределение и анализ ассоциаций гаплотипов NOX1 с риском развития СД2.

\begin{tabular}{|c|c|c|c|c|c|c|c|}
\hline SNPS & 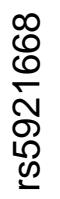 & 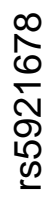 & 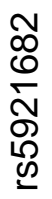 & Контроль & $\begin{array}{c}\text { Больные } \\
\text { СД2 }\end{array}$ & OR $(95 \% \mathrm{Cl})^{1}$ & $P$ \\
\hline$H 1$ & A & $\mathrm{C}$ & $\mathrm{G}$ & 0.3735 & 0.3943 & 1.00 & --- \\
\hline $\mathrm{H} 2$ & A & C & A & 0.2207 & 0.2351 & $1.00(0.84-1.18)$ & 0.96 \\
\hline$H 3$ & $\mathrm{G}$ & $\mathrm{T}$ & A & 0.233 & 0.2135 & $0.87(0.74-1.03)$ & 0.1 \\
\hline $\mathrm{H} 4$ & $\mathrm{G}$ & $\mathrm{T}$ & $G$ & 0.0761 & 0.0828 & $1.02(0.78-1.34)$ & 0.87 \\
\hline H5 & A & $\mathrm{T}$ & $A$ & 0.0626 & 0.0425 & $0.68(0.50-0.91)$ & 0.011 \\
\hline$H 6$ & A & $\mathrm{T}$ & $G$ & 0.0135 & 0.0209 & $1.37(0.79-2.36)$ & 0.26 \\
\hline редкие & * & * & * & 0.0091 & 0.007 & $0.53(0.31-0.89)$ & 0.017 \\
\hline
\end{tabular}

Анализ связи изучаемых SNPs с биохимическими показателями выявил, что уровень гликированного гемоглобина у носителей генотипа Т/T rs5921678 на 3,96 ммоль/л выше, чем у носителей референсного аллеля $\mathrm{C}(\mathrm{P}=0,01)$.

Таким образом, в проведенном исследовании впервые в русской популяции установлена ассоциация rs5921678 гена NOX1 с пониженным риском развития СД2. Протективный эффрект данного варианта в отношении заболевания объясняется менее выраженным синтезом супероксид-продуцирующего фермента НАДФН-оксидазы у носителей минорного аллеля Т, что проявляется снижением окислительного стресса.

Работа выполнена при финансовой поддержке Российского научного фонда (проект № 20-15-00227).

\section{Литература}

1. Wendt, Maria C., et al. "Differential effects of diabetes on the expression of the gp91phox homologues nox1 and nox4." Free Radical Biology and Medicine 39.3 (2005): 381-391. Edghill E.L., Bingham C., Ellard S., Hattersley A.T. Mutations in hepatocyte nuclear factor-1beta and their related phenotypes. J Med Genet 2006; 43: 84-90. doi.org/10.1136/jmg.2005.032854.

2. World Health Organization et al. Global status report on noncommunicable diseases 2014. - World Health Organization, 2014. - №. WHO/NMH/NVI/15.1.

3. Solé X., Guinó E., Valls J., Iniesta R., Moreno V. SNPStats: a web tool for the analysis of association studies. Bioinformatics 2006; 22(15): 1928-1929. doi.org/10.1093/bioinformatics/btl268.

4. GTEx Consortium. "The Genotype-Tissue Expression (GTEx) pilot analysis: Multitissue gene regulation in humans." Science 348.6235 (2015): 648-660. 
Polymorphic variants at NOX1 gene and the risk of type 2 diabetes mellitus

E. Klyosova*, I. Azarova, A. Polonikov

Kursk State Medical University

3 Karl Marx Street, 305041 Kursk, Russia.

*Email: ecless@yandex.ru

An association of the rs5921678 at the NOX1 gene with a risk of developing type 2 diabetes in the Russian population in females has been established.

Keywords: NOX1, single nucleotide polymorphism, NADPH oxidase, body mass index, blood glucose, type 2 diabetes mellitus 